\title{
Cholinergic Basal Forebrain Neurons Burst with Theta during Waking and Paradoxical Sleep
}

\author{
Maan Gee Lee, ${ }^{1,2}$ Oum K. Hassani, ${ }^{1}$ Angel Alonso, ${ }^{1}$ and Barbara E. Jones ${ }^{1}$ \\ ${ }^{1}$ Department of Neurology and Neurosurgery, Montreal Neurological Institute, McGill University, Montreal, Quebec, Canada H3A 2B4, and ${ }^{2}$ Department of \\ Pharmacology, School of Medicine, Kyungpook National University, Daegu 700-422, South Korea
}

It is known that acetylcholine can stimulate activation and promote plasticity in the cerebral cortex, yet it is not known how the cholinergic basal forebrain neurons, which release acetylcholine in the cortex, discharge in relation to natural cortical activity and sleep-wake states. By recording basal forebrain units in association with electroencephalographic activity across the sleep-wake cycle and labeling individual neurons with Neurobiotin for immunohistochemical identification, we show for the first time that cholinergic neurons discharge in bursts at maximal rates during active waking and paradoxical sleep, when gamma and theta electroencephalographic activity are maximal. They virtually cease firing during slow-wave sleep. Notably, their bursting discharge is synchronized with theta oscillations. Through their maximal firing and rhythmic theta discharge during active waking and paradoxical sleep, the cholinergic neurons can thus modulate the cortex to promote activation along with plasticity during these two states.

Key words: acetylcholine; cortical activation; gamma; juxtacellular labeling; plasticity; rat

\section{Introduction}

Early pharmacological studies showed that blocking the action of acetylcholine (ACh) prevents the cortical activation that normally occurs during waking and paradoxical sleep (PS), also called rapid eye movement sleep (REMS), and is marked by fast electroencephalogram (EEG) activity (Vanderwolf, 1975; Jones, 2004). Cholinergic antagonists also negatively affect learning and memory (Hasselmo and McGaughy, 2004). In patients with Alzheimer's disease, who show decrements of fast cortical activity and memory (Prinz et al., 1982), there is a loss of cholinergic basal forebrain neurons that supply the cholinergic innervation to the cerebral cortex (Davies and Maloney, 1976; Mesulam, 2004). Electrical or chemical stimulation of the basal forebrain in animals promotes cortical activation and plasticity that are accompanied by gamma $(30-60 \mathrm{~Hz})$ and theta $(4-8 \mathrm{~Hz})$ oscillations (Greenstein et al., 1988; Metherate et al., 1992; Maloney et al., 1997; Kilgard and Merzenich, 1998; Cape and Jones, 2000; Cape et al., 2000; McLin et al., 2002). Microdialysis studies have indicated that ACh release is increased with cortical activation in association with attentive waking (Himmelheber et al., 2000) and PS compared with slow-wave sleep (SWS) (Marrosu et al., 1995). The cholinergic neurons are thus assumed to discharge at higher rates in association with cortical activation during waking and PS; however, neurons recorded in the basal forebrain during natural states have not been identified by their neurotransmitter (Detari

Received Jan. 13, 2005; revised March 1, 2005; accepted March 23, 2005.

This research was supported by Canadian Institutes of Health Research Grant 13458 and National Institutes of Health Grant NIH R01 MH-60119-01A (B.E.J.). We thank Lynda Mainville and Pablo Henny for assistance with the histochemistry.

Correspondence should be addressed to Barbara E. Jones, Montreal Neurological Institute, 3801 University Street, Montreal, Quebec, Canada H3A 2B4. E-mail: barbara.jones@mcgill.ca.

DOI:10.1523/JNEUROSCI.0178-05.2005

Copyright $\odot 2005$ Society for Neuroscience $\quad$ 0270-6474/05/254365-05\$15.00/0 et al., 1984; Szymusiak and McGinty, 1986; Buzsaki et al., 1988). Moreover, the cholinergic neurons represent only 5\% (I. Gritti, L. Mainville, and B. E. Jones, unpublished observations) of the total basal forebrain cell population, which is both chemically (Gritti et al., 2003) and physiologically (Lee et al., 2004) heterogeneous. Thus, the discharge pattern and profile of cholinergic neurons in relation to natural cortical activity and sleep-wake states were unknown when the present study was undertaken.

To record and identify neurons as cholinergic in naturally sleeping-waking animals, we used extracellular recording and juxtacellular labeling of single units (Pinault, 1996) that we had applied previously in anesthetized rats (Manns et al., 2000) and adapted subsequently for use in unanesthetized, head-fixed rats (Lee et al., 2004). One neuron per side that was recorded in association with EEG and electromyogram (EMG) activity during a full sleep-wake cycle was labeled with Neurobiotin (Nb) for subsequent immunohistochemical staining for choline acetyltransferase (ChAT). We report a distinct firing pattern and profile of the identified cholinergic neurons.

\section{Materials and Methods}

Surgery and recording. All procedures were approved by the McGill University Animal Care Committee and the Canadian Council on Animal Care; these procedures also met international standards. Forty-five adult Long-Evans rats (200-250 g; Charles River, St. Constant, Quebec, Canada) were deeply anesthetized with ketamine, xylazine, and acepromazine $(65: 5: 1 \mathrm{mg} / \mathrm{kg}$ in a mixture of $2 \mathrm{ml} / \mathrm{kg}$ initial dose and $1 \mathrm{ml} / \mathrm{kg}$ booster as needed, i.p.) for implantation of a metal U-frame to hold the head by screws to a sliding carriage adapter within the stereotaxic frame (Souliere et al., 2000) along with EEG and EMG electrodes, as described previously (Lee et al., 2004). For the EEG, small screws were threaded into the skull so that they were in contact with the dura over the anterior medial prefrontal (PF) cortex, the retrosplenial (RS) (also known as the posterior cingulate) cortex, the parietal $(\mathrm{P})$ cortex, and the occipital $(\mathrm{O})$ 
cortex of each side and over the olfactory bulb (OB) on one side. One screw was placed in the frontal bone between the frontal lobes and olfactory bulbs to serve as a reference. After recovery from surgery ( $2 \mathrm{~d})$, the animals were habituated to the head fixation (6-9 d). While lying in a Plexiglas box, they were prevented from twisting their bodies but otherwise able to move their bodies and limbs relatively freely; they were able to sleep in a sphinx position. After adaptation, the rats were anesthetized once again (as above). Holes were drilled in the skull, and the dura was opened over the basal forebrain areas of each side. After $1 \mathrm{~d}$ of recovery, daily recording sessions of $\sim 6 \mathrm{~h}$ were performed for a maximum of $5 \mathrm{~d}$. Single units were recorded using glass micropipettes $(\sim 1 \mu \mathrm{m}$ tip $)$ that were filled with $0.5 \mathrm{M} \mathrm{NaCl}$ and $\sim 5 \% \mathrm{Nb}$ (Vector Laboratories, Burlingame, CA) and an intracellular amplifier (Neurodata IR-283A; Cygnus Technology, Delaware Water Gap, PA). The unit signal was amplified $(2000 \times)$ and filtered $(0.3-3 \mathrm{kHz})$ using CyberAmp 380 (Axon Instruments, Union City, CA) and then acquired at $16 \mathrm{kHz}$ for on-line viewing with Axoscope (version 8.1; Axon Instruments) to verify that the recorded activity was derived from a single unit. The unit signal was simultaneously acquired and digitized at $8 \mathrm{kHz}$ together with EEG and EMG signals (amplified, filtered, and digitized at $250 \mathrm{~Hz}$ by CyberAmp 380) for recording and analysis using EEG and sleep-wake state-dedicated software (Harmonie version 5.2; Stellate Company, Montreal, Quebec, Canada). A video recording of the rats' behavior was also acquired simultaneously by the same software. On the last day of recording from one side, the last cell recorded during active wake (aW), SWS, and PS was labeled with $\mathrm{Nb}$ using the juxtacellular technique, as described previously (Manns et al., 2000; Lee et al., 2004).

Data analysis. For analysis, units were selected that had been recorded for $>5 \mathrm{~min}$ and during at least one episode of aW, SWS, and PS. Together with the synchronized video images of behavior, electrophysiological records of EEG and EMG were scored (using Harmonie) by 10 s epochs for sleep-wake states as described previously (Maloney et al., 1997; Lee et al., 2004). The unit activity was subsequently analyzed per $10 \mathrm{~s}$ epoch in each sleep-wake state for average discharge rate (spikes per second), instantaneous firing frequency using the first modal peak of the interspike interval histogram (ISIH), rhythmicity of discharge and its frequency using the autocorrelation histogram ( $\mathrm{ACH})$, and crosscorrelated EEG activity using the spike-triggered average (STA). Gamma $(30-58 \mathrm{~Hz})$ power, delta $(1-4.5 \mathrm{~Hz})$ power, and theta $(4.5-8 \mathrm{~Hz})$ activity (measured as the ratio of theta/delta powers) were measured per epoch along with EMG amplitude $(30-100 \mathrm{~Hz})$ for correlation with unit spike rate. Units were classified in groups according to whether their discharge rate varied significantly across states $(p<0.05$ by ANOVA) and, if so, according to the state during which their maximal discharge rate occurred ( $p<0.05$ by post hoc paired comparisons) (Lee et al., 2004). Units were characterized further according to their pattern of discharge and classified as being either tonic or phasic by comparison of the average discharge rate interval with the ISIH distribution (Lee et al., 2004).

Histochemistry. After the recording and labeling of units, the rats were given an overdose of sodium pentobarbital (Somnotol; $\sim 100 \mathrm{mg} / \mathrm{kg}$, i.p.) and perfused with a $4 \%$ paraformaldehyde solution. After immersion in $30 \%$ sucrose for $2-3 \mathrm{~d}$, brains were frozen for storage and subsequently cut into $25-\mu \mathrm{m}$-thick sections. For revelation of $\mathrm{Nb}$, sections were incubated for $2.5 \mathrm{~h}$ in cyanine 2 (Cy2)-conjugated streptavidin (1:1000; Jackson ImmunoResearch, West Grove, PA). After location of an $\mathrm{Nb}$-labeled cell, the relevant section was incubated overnight at room temperature in rabbit anti-ChAT antiserum (1:1000; Chemicon International, Temecula, CA) and subsequently for $2 \mathrm{~h}$ in $\mathrm{Cy} 3$-conjugated donkey anti-rabbit $(\mathrm{Rb})$ antiserum (1:1000; Jackson ImmunoResearch). Nblabeled cells were located by epifluorescence using a Leica (Nussloch, Germany) DMLB microscope. Images of the labeled cells were acquired, and their location was mapped onto a computer resident atlas with the aid of Neurolucida (version 5; MicroBrightField, Williston, VT).

\section{Results}

Of the units recorded during aW, SWS, and PS, which included 123 fully characterized units (Lee et al., 2004) and 227 other acquired units $(n=350), 34$ (of 62 attempted) neurons were successfully labeled with $\mathrm{Nb}$ (Fig. 1). The Nb-labeled cells were

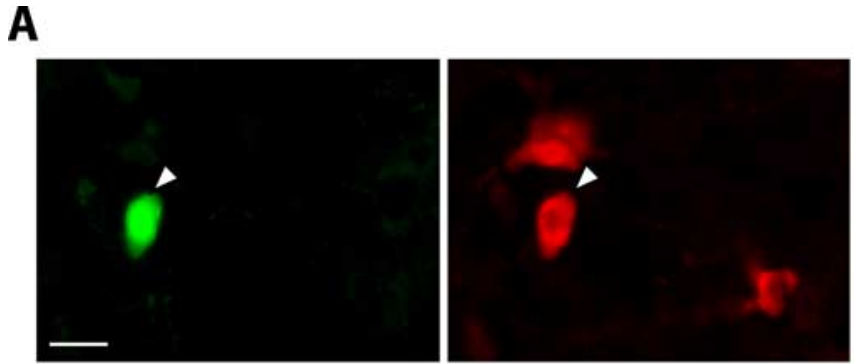

B

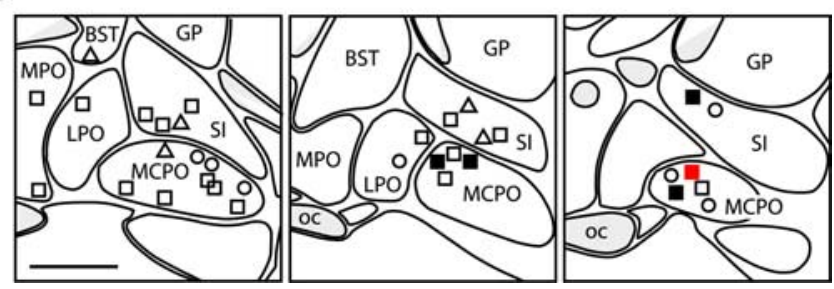

Figure 1. Location and classification of Nb-labeled neurons. A, Image of a cell (\#c30u13) labeled with $\mathrm{Nb}$ (stained by green fluorescent $\mathrm{Cy} 2$ ) and immunopositive for $\mathrm{ChAT}$ (stained by red (y3). Scale bar, $20 \mu \mathrm{m}$. B, Plots of Nb-labeled neurons $(n=34)$ through the basal forebrain (from left to right at approximately $-0.40,-0.92$, and $-1.30 \mathrm{~mm}$ from bregma) that were classified as discharging maximally during aW (circle), SWS (triangle), or PS (square) and distinguished as cholinergic ( $\mathrm{Nb}+/ \mathrm{ChAT}+$; filled symbols including one in red for the cell shown in $A$ ) or noncholinergic ( $\mathrm{Nb}+/ \mathrm{ChAT}-$; open symbols). BST, Bed nucleus of the stria terminalis; GP, globus pallidus; LPO, lateral preoptic area; MPO, medial preoptic nucleus; oc, optic chiasm. Scale bar, $1 \mathrm{~mm}$.

located within the magnocellular preoptic nucleus (MCPO) $(n=$ $18)$, the substantia innominata (SI) $(n=10)$, or adjacent regions $(n=6): 29$ were negative for ChAT, and 5 were positive for ChAT and located in the MCPO $(n=4)$ or SI $(n=1)$ (Fig. $1 A, B)$. As classified according to the state in which they discharged at their maximal rate (Lee et al., 2004), aW maximally active (maxactive) cells were all negative for ChAT (7 of 34). Similarly SWS max-active cells were all negative for ChAT (5 of 34). Among those cells that were classified as PS max-active, most were negative for ChAT (17 of 34), but several were positive for ChAT (5 of 34).

The $\mathrm{Nb}+/ \mathrm{ChAT}+$ cells discharged in bursts of spikes during aW, transition to PS (tPS), and PS (Fig. 2). They were virtually silent during SWS. Across the three major states, the average discharge rate was highest during PS $[16.3 \pm 0.98 \mathrm{~Hz}$ (mean \pm SEM); $n=5$ ], intermediate during aW $(7.61 \pm 1.62 \mathrm{~Hz})$, and lowest during SWS $(0.84 \pm 0.42 \mathrm{~Hz}$ ) (according to ANOVA for state; $F=41.6 ; \mathrm{df}=4 ; p<0.001$; post hoc pairwise comparisons; $p<0.05)$. In all cells, the average discharge rate decreased from aW to quiet wake ( $\mathrm{qW}$ ) and from $\mathrm{qW}$ into the transition to SWS (tSWS) and SWS; it increased during tPS to be maximal during PS (Fig. $3 A, B$ ). Across the sleep-wake cycle, the average discharge rate was strongly and positively correlated with EEG gamma power $[r=0.91 \pm 0.03($ mean \pm SEM); $n=5]$ and theta activity $(r=0.85 \pm 0.05)$; it was negatively correlated with delta power $(r=-0.77 \pm 0.08)$ and was not correlated with neckmuscle EMG amplitude $(r=0.13 \pm 0.10)$. The discharge pattern of all cholinergic neurons was phasic and characterized by highfrequency spike bursts during aW, tPS, and PS, as shown in the recording (Fig. 2, expanded traces) and the ISIHs for these states (Fig. 3E, PS). During PS, the mean \pm SEM intraburst frequency (calculated from the primary mode of the ISIH) was $107.72 \pm$ $17.50 \mathrm{~Hz}$ (with a range of $60-148 \mathrm{~Hz} ; n=5$ ). The bursting was rhythmic in most neurons, as evident in the recording (Fig. 2) 

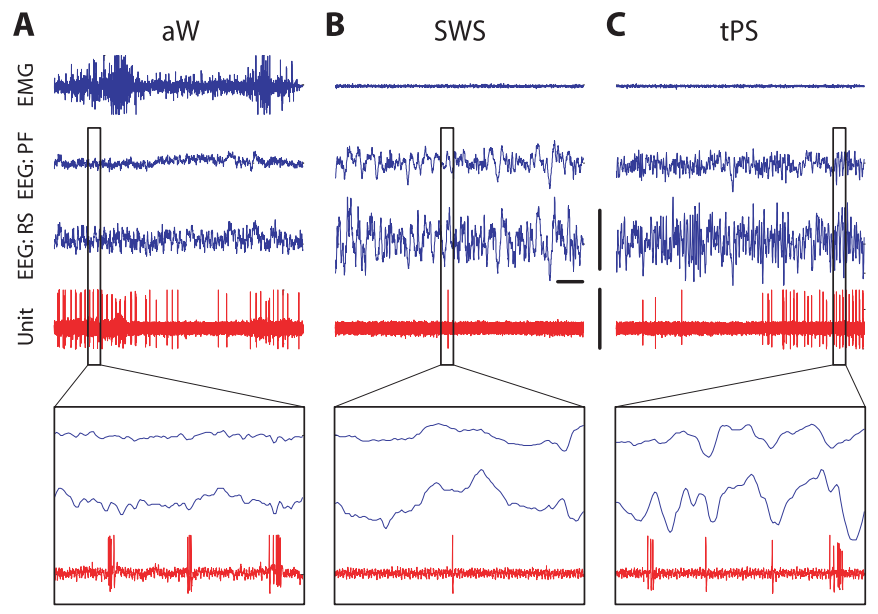

D PS

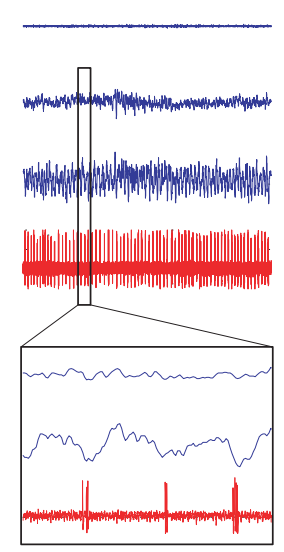

Figure 2. Discharge of an Nb-labeled cholinergic neuron. $\boldsymbol{A}-\boldsymbol{D}$, Record of $\mathrm{Nb}+/ \mathrm{ChAT}+$ unit discharge (Fig. 1A, \#c30u13) together with EEG and EMG activity during 10 s periods of aW $(\boldsymbol{A}), \operatorname{SWS}(\boldsymbol{B}), \mathrm{tPS}(\boldsymbol{C})$, and PS (D). The unit fired during aW, virtually ceased firing during SWS, resumed firing during $\mathrm{PSS}$, and discharged maximally during PS. As evident in the expanded $0.5 \mathrm{~s}$ traces (bottom), the unit discharged in bursts of spikes with theta EEG activity that was present intermittently during aW, briefly at the end of tPS, and continuously during PS. Calibration: $1 \mathrm{~s}, 1 \mathrm{mV}$ (EEG, EMG), $1.5 \mathrm{mV}$ (Unit).

A
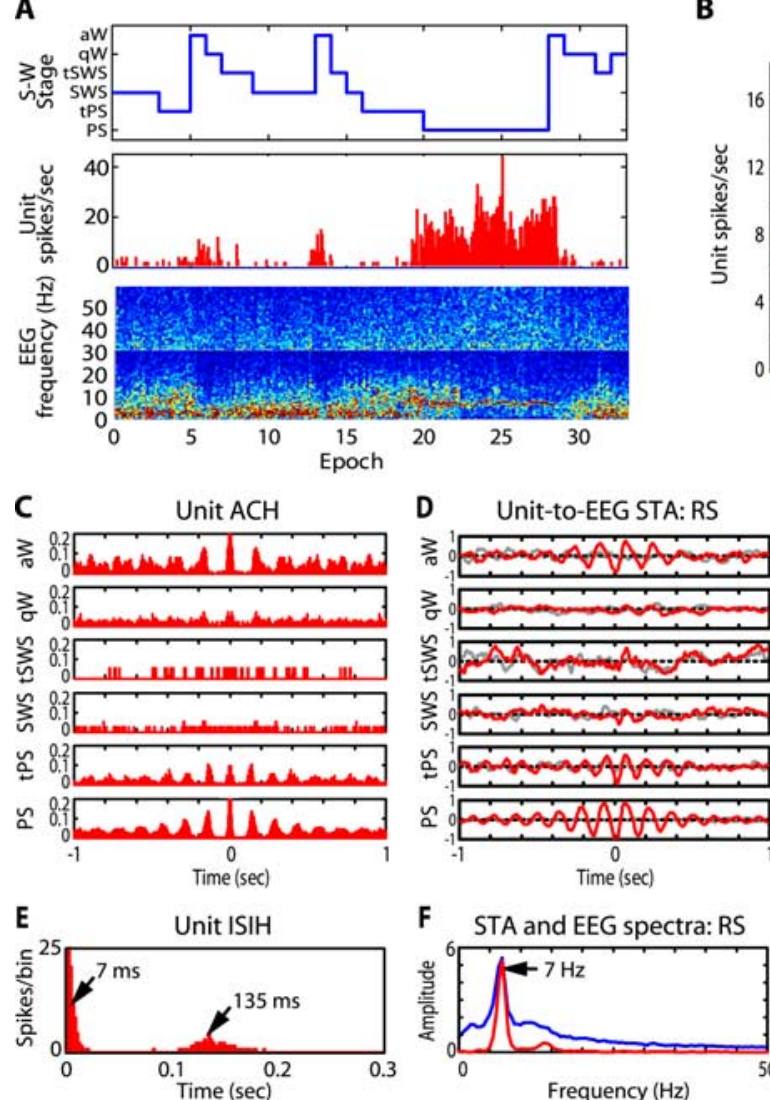

F STA and EEG spectra: RS
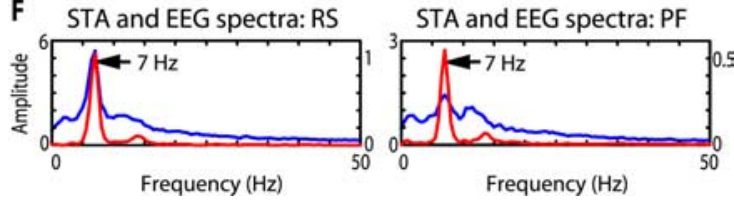

Figure 3. Discharge profile and pattern of an Nb-labeled cholinergic neuron. A, Across sleep-wake (S-W) states (shown in the sleep-wake hypnogram), the $\mathrm{Nb}+/ \mathrm{ChAT}+$ cell (Figs. 1A, 2, \#c30u13) discharged at variable rates (shown in unit rate histogram) in association with variable EEGs (shown in power spectral array). $\boldsymbol{B}$, Its average discharge rate was moderately high in aW, minimal in SWS, and maximal in PS. C, Its discharge pattern was rhythmic during aW, tPS, and PS (shown in the ACHs). D, Its firing was significantly cross-correlated with the EEG during PS on both the RS and PF cortex (evident in the Unit-to-EEG STA in red compared with the shuffled train in gray). $\boldsymbol{E}$, Its rhythmic discharge occurred in high-frequency bursts of spikes ( $\sim 143 \mathrm{~Hz})$ at regular intervals corresponding to a theta oscillation (according to the first and second smoothed modes of the ISIH for PS). $\boldsymbol{F}$, Its EEG-correlated discharge occurred at a theta frequency with a peak of $7 \mathrm{~Hz}$ (evident in the power spectra of the Unit-to-EEG STA shown in red) that also corresponded to the prominent peak of the EEG activity (in blue) on both the RS cortex and the PF cortex during PS. and ACHs during aW, tPS, and PS (Fig. $3 C$ ). During PS, when the rhythmic bursting along with theta was the most continuous, the interburst frequency was $6-7$ $\mathrm{Hz}$. The burst discharge was significantly cross-correlated with EEG theta activity at the same frequency during PS on the RS cortex (in four of five cells) (Fig. 3D) and also on the PF cortex (Fig. 3D), the OB, the $\mathrm{P}$ cortex, and the $\mathrm{O}$ cortex (data not shown). A corresponding theta peak was evident on the EEG spectra in these regions (Fig. 3F). The rhythmic burst discharge and cross-correlated theta activity were less consistently evident during active waking epochs than during PS epochs because of the transient appearance of theta activity, which occurs with intermittent movements during waking, in contrast to the continuous appearance of theta activity, which occurs during PS (Figs. 2, 3).

$\mathrm{Nb}$-labeled cholinergic cells were distinguished from the noncholinergic cells by their profile and pattern of discharge. Noncholinergic cells included aW maxactive cells ( 7 of 29), the discharge of which is positively correlated with EMG, SWS max-active cells (5 of 29), the discharge of which is positively correlated with delta EEG, and PS max-active cells (17 of 29), the discharge of which is positively correlated with gamma EEG activity across sleep-wake states (Lee et al., 2004). The majority discharged in a tonic pattern (18 of 29); the minority discharged in a phasic pattern (11 of 29). Of the PS max-active noncholinergic cells, most discharged in a tonic mode (9 of 17), although many discharged in a phasic mode (8 of 17). None shared the same profile or pattern of discharge as the cholinergic cells, although two cells did show theta rhythmicity in their firing during PS and discharged similarly to rhythmically discharging noncholinergic cells identified previously in anesthetized rats (Manns et al., 2003).

Among the basal forebrain cells that were recorded across sleep-wake states and fully characterized, although not labeled with $\mathrm{Nb}$, in a previous study (Lee et al., 2004), four cells showed exactly the same profile and pattern of discharge as the present Nb-labeled-ChAT + cells. They discharged at the highest rate during PS $(20.24 \pm 2.89 \mathrm{~Hz})$, at an intermediate rate in aW $(8.15 \pm 1.28 \mathrm{~Hz})$, and at the lowest rate in SWS $(1.03 \pm 0.05 \mathrm{~Hz})$, as discharging in bursts (with a mean intraburst frequency of $88.34 \pm 16.05)$ and as discharging rhythmically (with an interburst frequency of $6-7 \mathrm{~Hz}$ ) in a crosscorrelated manner with EEG theta activity on the RS cortex ( $n=4$ of 4 ), as well as on 
other PF, OB, P, and $\mathrm{O}$ cortices. These unlabeled "cholinergiclike" cells, together with the $\mathrm{Nb}+/ \mathrm{ChAT}+$ cells of the same cohort, represented $\sim 5 \%$ of the fully characterized basal forebrain neurons.

\section{Discussion}

We reveal for the first time the discharge pattern and profile of cholinergic basal forebrain neurons in unanesthetized animals, in association with natural cortical activities and across natural sleep-wake states. Previous recording studies in unanesthetized animals of neurons in the MCPO-SI (Detari et al., 1984; Szymusiak and McGinty, 1986; Buzsaki et al., 1988), as well as in the medial septum-diagonal band (MS-DB) (King et al., 1998), discovered multiple cell types with no suitable means to identify which were cholinergic. Here, using juxtacellular labeling with $\mathrm{Nb}$ together with immunohistochemical staining for ChAT in head-fixed rats, we unambiguously identify cholinergic cells within the MCPO-SI that represent $\sim 5 \%$ of all neurons in the region. As we had found originally in brain slices (Khateb et al., 1992) and subsequently in anesthetized rats (Manns et al., 2000), the cholinergic cells discharged in high-frequency spike bursts. Here, this bursting discharge was shown to be associated with natural cortical activation, including gamma and theta activity, and to occur during the states of aW and PS.

We show for the first time that cholinergic basal forebrain neurons discharge at their maximal rate in association with spontaneous cortical activation when gamma activity, which reflects cortical arousal (Maloney et al., 1997), is maximal. Indeed, across states, the discharge rate of cholinergic neurons was highly and positively correlated with gamma power $(\sim 0.90)$ and could thus promote gamma activity on the cerebral cortex. ACh released from the cholinergic terminals can stimulate this high-frequency activity by depolarizing pyramidal cells or interneurons through slow muscarinic actions (Metherate et al., 1992; Buhl et al., 1998).

We show for the first time that cholinergic basal forebrain neurons, which are known to project to the neocortex, discharge in a cross-correlated manner with theta activity and could thus contribute to theta modulation of cortical cells and to the generation of cortical theta activity. Theta rhythm, first recorded in the hippocampus, was long believed to be recorded on the overlying cortex as a result of volume conduction, yet it was subsequently shown to be generated in the posterior cingulate cortex by theta bursting neurons (Leung and Borst, 1987). Theta rhythm was also eliminated from the hippocampus but not the cingulate cortex after lesions of the MS-DB, suggesting a separate pathway for generating cortical theta (Borst et al., 1987), which our results indicate could originate from MCPO-SI neurons. With the recording used here, we cannot confirm that the theta recorded from the surface of the RS (also known as the posterior cingulate) cortex or other cortical regions was generated locally as opposed to being recorded through volume conduction from the hippocampus; however, we know from both anatomical studies (Gritti et al., 1997) and antidromic activation of rhythmically bursting cholinergic neurons in the anesthetized rat (Manns et al., 2000) that cholinergic neurons in the MCPO-SI project to the neocortex, including the RS and the PF cortex, and thus can transmit a theta rhythmic signal to the neocortex that can rhythmically modulate the firing behavior of the cortical cells. Interestingly, theta waves similar to those recorded in rats have been recorded recently in humans over the neocortex as well as in the hippocampus and have been found, as in rats, to be associated with memory processing (Raghavachari et al., 2001; Cantero et al., 2003). Theta burst stimulation and application of the cholin- ergic agonist carbachol, which induces theta-like oscillations, promote synaptic plasticity in hippocampal slices (Larson et al., 1986; Huerta and Lisman, 1993). The bursting discharge of the cholinergic basal forebrain neurons shown here could thus stimulate theta along with plasticity in the neocortex. These effects could be elicited in part through slow muscarinic actions but also by faster nicotinic actions on cortical interneurons (Xiang et al., 1998; Christophe et al., 2002).

Finally, we show for the first time that the cholinergic basal forebrain neurons discharge maximally during aW and PS, whereas they virtually cease firing during SWS. By stimulating gamma and theta in the cerebral cortex, cholinergic neurons would thus be expected to enhance plasticity in association with those activities periodically during active or attentive periods of waking and relatively continuously during PS. For the latter, there is evidence to show that during PS or REMS when dreaming occurs, memory traces are reactivated, enhanced, and even transformed into new insights (Winson, 1993; Karni et al., 1994; Smith, 1995; Maquet et al., 2000; Louie and Wilson, 2001; Wagner et al., 2004). It is indeed fitting, if not ironic, that Otto Loewi claims that the design of the key experiment for his discovery of cholinergic transmission in 1921 came to him in a dream (Mazzarello, 2000).

\section{References}

Borst JGG, Leung L-WS, MacFabe DF (1987) Electrical activity of the cingulate cortex. II. Cholinergic modulation. Brain Res 407:81-93.

Buhl EH, Tamas G, Fisahn A (1998) Cholinergic activation and tonic excitation induce persistent gamma oscillations in mouse somatosensory cortex in vitro. J Physiol (Lond) 513:117-126.

Buzsaki G, Bickford RG, Ponomareff G, Thal LJ, Mandel R, Gage FH (1988) Nucleus basalis and thalamic control of neocortical activity in the freely moving rat. J Neurosci 8:4007-4026.

Cantero JL, Atienza M, Stickgold R, Kahana MJ, Madsen JR, Kocsis B (2003) Sleep-dependent theta oscillations in the human hippocampus and neocortex. J Neurosci 23:10897-10903.

Cape EG, Jones BE (2000) Effects of glutamate agonist versus procaine microinjections into the basal forebrain cholinergic cell area upon gamma and theta EEG activity and sleep-wake state. Eur J Neurosci 12:2166-2184.

Cape EG, Manns ID, Alonso A, Beaudet A, Jones BE (2000) Neurotensininduced bursting of cholinergic basal forebrain neurons promotes gamma and theta cortical activity together with waking and paradoxical sleep. J Neurosci 20:8452-8461.

Christophe E, Roebuck A, Staiger JF, Lavery DJ, Charpak S, Audinat E (2002) Two types of nicotinic receptors mediate an excitation of neocortical layer I interneurons. J Neurophysiol 88:1318-1327.

Davies P, Maloney AJ (1976) Selective loss of central cholinergic neurones in Alzheimer's disease. Lancet 2:1403.

Detari L, Juhasz G, Kukorelli T (1984) Firing properties of cat basal forebrain neurones during sleep-wakefulness cycle. Electroencephalogr Clin Neurophysiol 58:362-368.

Greenstein YJ, Pavlides C, Winson J (1988) Long-term potentiation in the dentate gyrus is preferentially induced at theta rhythm periodicity. Brain Res 438:331-334.

Gritti I, Mainville L, Mancia M, Jones BE (1997) GABAergic and other noncholinergic basal forebrain neurons project together with cholinergic neurons to meso- and iso-cortex in the rat. J Comp Neurol 383:163-177.

Gritti I, Manns ID, Mainville L, Jones BE (2003) Parvalbumin, calbindin, or calretinin in cortically projecting and GABAergic, cholinergic, or glutamatergic basal forebrain neurons of the rat. J Comp Neurol 458:11-31.

Hasselmo ME, McGaughy J (2004) High acetylcholine levels set circuit dynamics for attention and encoding and low acetylcholine levels set dynamics for consolidation. Prog Brain Res 145:207-231.

Himmelheber AM, Sarter M, Bruno JP (2000) Increases in cortical acetylcholine release during sustained attention performance in rats. Brain Res Cogn Brain Res 9:313-325.

Huerta PT, Lisman JE (1993) Heightened synaptic plasticity of hippocam- 
pal CA1 neurons during a cholinergically induced rhythmic state. Nature 364:723-725.

Jones BE (2004) Activity, modulation and role of basal forebrain cholinergic neurons innervating the cerebral cortex. Prog Brain Res 145:157-169.

Karni A, Tanne D, Rubenstein BS, Askenasy JJ, Sagi D (1994) Dependence on REM sleep of overnight improvement of a perceptual skill. Science 265:679-682.

Khateb A, Muhlethaler M, Alonso A, Serafin M, Mainville L, Jones BE (1992) Cholinergic nucleus basalis neurons display the capacity for rhythmic bursting activity mediated by low threshold calcium spikes. Neuroscience 51:489-494.

Kilgard MP, Merzenich MM (1998) Cortical map reorganization enabled by nucleus basalis activity. Science 279:1714-1718.

King C, Recce M, O'Keefe J (1998) The rhythmicity of cells of the medial septum/diagonal band of Broca in the awake freely moving rat: relationships with behaviour and hippocampal theta. Eur J Neurosci 10:464-477.

Larson J, Wong D, Lynch G (1986) Patterned stimulation at the theta frequency is optimal for the induction of hippocampal long-term potentiation. Brain Res 368:347-350.

Lee MG, Manns ID, Alonso A, Jones BE (2004) Sleep-wake related discharge properties of basal forebrain neurons recorded with micropipettes in head-fixed rats. J Neurophysiol 92:1182-1198.

Leung L-WS, Borst JGG (1987) Electrical activity of the cingulate cortex. I. Generating mechanisms and relations to behavior. Brain Res 407:68-80.

Louie K, Wilson MA (2001) Temporally structured replay of awake hippocampal ensemble activity during rapid eye movement sleep. Neuron 29:145-156.

Maloney KJ, Cape EG, Gotman J, Jones BE (1997) High frequency gamma electroencephalogram activity in association with sleep-wake states and spontaneous behaviors in the rat. Neuroscience 76:541-555.

Manns ID, Alonso A, Jones BE (2000) Discharge properties of juxtacellularly labeled and immunohistochemically identified cholinergic basal forebrain neurons recorded in association with the electroencephalogram in anesthetized rats. J Neurosci 20:1505-1518.

Manns ID, Alonso A, Jones BE (2003) Rhythmically discharging basal forebrain units comprise cholinergic, GABAergic, and putative glutamatergic cells. J Neurophysiol 89:1057-1066.

Maquet P, Laureys S, Peigneux P, Fuchs S, Petiau C, Phillips C, Aerts J, Del Fiore G, Degueldre C, Meulemans T, Luxen A, Franck G, Van Der Linden M, Smith C, Cleeremans A (2000) Experience-dependent changes in cerebral activation during human REM sleep. Nat Neurosci 3:831-836.
Marrosu F, Portas C, Mascia S, Casu MA, Fa M, Giagheddu M, Imperato A, Gessa GL (1995) Microdialysis measurement of cortical and hippocampal acetylcholine release during sleep-wake cycle in freely moving cats. Brain Res 671:329-332.

Mazzarello P (2000) What dreams may come? Nature 408:523.

McLin III DE, Miasnikov AA, Weinberger NM (2002) Induction of behavioral associative memory by stimulation of the nucleus basalis. Proc Natl Acad Sci USA 99:4002-4007.

Mesulam M (2004) The cholinergic lesion of Alzheimer's disease: pivotal factor or side show? Learn Mem 11:43-49.

Metherate R, Cox CL, Ashe JH (1992) Cellular bases of neocortical activation: modulation of neural oscillations by the nucleus basalis and endogenous acetylcholine. J Neurosci 12:4701-4711.

Pinault D (1996) A novel single-cell staining procedure performed in vivo under electrophysiological control: morpho-functional features of juxtacellularly labeled thalamic cells and other central neurons with biocytin or Neurobiotin. J Neurosci Methods 65:113-136.

Prinz PN, Vitaliano PP, Vitiello V, Bokan J, Raskind M, Peskind E, Gerber C (1982) Sleep, EEG, and mental function changes in senile dementia of the Alzheimer's type. Neurobiol Aging 3:361-370.

Raghavachari S, Kahana MJ, Rizzuto DS, Caplan JB, Kirschen MP, Bourgeois B, Madsen JR, Lisman JE (2001) Gating of human theta oscillations by a working memory task. J Neurosci 21:3175-3183.

Smith C (1995) Sleep states and memory processes. Behav Brain Res 69:137-145.

Souliere F, Urbain N, Gervasoni D, Schmitt P, Guillemort C, Fort P, Renaud B, Luppi PH, Chouvet G (2000) Single-unit and polygraphic recordings associated with systemic or local pharmacology: a multi-purpose stereotaxic approach for the awake, anesthetic-free, and head-restrained rat. J Neurosci Res 61:88-100.

Szymusiak R, McGinty D (1986) Sleep-related neuronal discharge in the basal forebrain of cats. Brain Res 370:82-92.

Vanderwolf CH (1975) Neocortical and hippocampal activation in relation to behavior: effects of atropine, eserine, phenothiazines and amphetamine. J Comp Physiol Psychol 88:300-323.

Wagner U, Gais S, Haider H, Verleger R, Born J (2004) Sleep inspires insight. Nature 427:352-355.

Winson J (1993) The biology and function of rapid eye movement sleep. Curr Opin Neurobiol 3:243-248.

Xiang Z, Huguenard JR, Prince DA (1998) Cholinergic switching within neocortical inhibitory networks. Science 5379:985-988. 